
\title{
$\begin{array}{ll}\text { Research Square } & \begin{array}{l}\text { Preprints are preliminary reports that have not undergone peer review. } \\ \text { They should not be considered conclusive, used to inform clinical practice, } \\ \text { or referenced by the media as validated information. }\end{array}\end{array}$
}

\section{MiR-30a-5p regulates GLT-1 function via a PKCa-mediated ubiquitin degradation pathway in a mouse model of Parkinson's disease}

\author{
Xingjun Meng \\ Shunde Hospital of Southern Medical University \\ Jianping Zhong \\ Shunde Hospital of Southern Medical University \\ Chong Zeng \\ Shunde Hospital of Southern Medical University \\ Ken Kin Lam Yung \\ Hong Kong Baptist University \\ Xiuping Zhang \\ Southern Medical University \\ Xiaojuan Wu \\ Shunde Hospital of Southern Medical University \\ Shaogang Qu ( $\sim$ sgq9528@163.com ) \\ Shunde Hospital of Southern Medical University
}

Research

Keywords: Parkinson's disease, miR-30a-5p, GLT-1, ubiquitination, PKCa

Posted Date: February 20th, 2020

DOI: https://doi.org/10.21203/rs.2.24022/v1

License: (c) (i) This work is licensed under a Creative Commons Attribution 4.0 International License. Read Full License

Version of Record: A version of this preprint was published at ACS Chemical Neuroscience on April 21st, 2021. See the published version at https://doi.org/10.1021/acschemneuro.1c00076. 


\section{Abstract}

Background:Glutamate excitotoxicity caused by dysfunctional glutamate transporters plays an important role in the pathogenesis of Parkinson's disease (PD); however, the mechanisms that underlie the regulation of glutamate transporters in PD are still not fully elucidated. MicroRNAs have been reported to play key roles in regulating the translation of glutamate-transporter mRNA.

Methods: We established model of PD 1-methyl-4-phenyl-1,2,3,6-tetrahydropyridine (MPTP)-treated mice in vivo and 1-methyl-4-phenylpyridinium (MPP ${ }^{+}$) treated astrocyte in vitro. Stereotaxic injection of shRNA in mouse, and miRNA inhibitor/mimic, or antagonist/agonist treated the cell model, Behavioral experiments, glutamic acid uptake, transport activity of synaptosomes, underlying mechanisms and the impact on neuronal survival were assessed.

Results We demonstrated that short-hairpin RNA-mediated knockdown of miR-30a-5p ameliorated motor deficits and pathological changes like astrogliosis and reactive microgliosis in a mouse model of PD. Western blotting and immunofluorescent labeling revealed that miR-30a-5p suppressed the expression and function of GLT-1 in MPTP-treated mice and specifically in astrocytes treated with (cell model of PD).

Conclusion Both in vitro and in vivo, we found that miR-30a-5p knockdown promoted glutamate uptake and increased GLT-1 expression by hindering GLT-1 ubiquitination and subsequent degradation in a PKCa-dependent manner. Therefore, miR-30a-5p represents a potential therapeutic target for the treatment of PD.

\section{Background}

Parkinson's disease (PD) is an age-associated movement disorder whose pathological hallmark is the progressive death of dopaminergic cells in the substantia nigra pars compacta (SNpc) coupled with the accumulation of Lewy bodies containing alpha-synuclein (a-Syn) [1]. Several different mechanisms are believed to contribute to the death of dopaminergic (DA) neurons in PD, including genetic factors [2-5], environmental factors [6, 7], neuroinflammation [8-10] and glutamate excitotoxicity [11-16]. The role of glutamate excitotoxicity in the development of PD has become increasingly important in recent years. Glutamate transporters play a predominant role in clearing excess glutamate from the synaptic cleft. Five mammalian excitatory-amino-acid transporters (EAATs) have been characterized: glutamate/aspartate transporter (GLAST, also called EAAT1), glutamate transporter-1 (GLT-1, also called EAAT2), excitatory amino acid carrier-1 (EAAC1, also called EAAT3), EAAT4, and EAAT5[17-23. Among the glutamate transporters, GLT-1, found on astrocytes, is the most critical in the development of PD because it is responsible for the uptake of nearly $90 \%$ of synaptic glutamate $[14,24]$.

Based on our previous studies, upregulation of GLT-1 could significantly improve the motor deficits and pathological changes in mice treated with 1-methyl-4phenyl-1,2,3,6-tetrahydropyridine (MPTP) $[14,15]$. We showed that rapamycin and Nedd4-2 knockdown ameliorated movement abnormalities in a PD mouse model and increased tyrosine hydroxylase $(\mathrm{TH})$ expression in the midbrain and striatum of MPTP-treated mice by increasing the expression and function of GLT-1 $[14,15]$. These results suggest that the regulation of GLT-1 could be a promising strategy to treat PD. However, the abnormal mechanism of GLT-1 in PD has not been fully elucidated.

MicroRNAs (miRNA) are short sequences of non-coding RNA (average length of 22 nucleotides) that bind to the 3囚-untranslated region (3区-UTR) of messenger RNA (mRNA) with less-than-perfect complementarity. MiRNAs are very crucial regulators of protein expression because their binding to mRNA results in degradation of the mRNA or repression of its translation [25]. MiRNAs are involved in numerous biological processes, including proliferation, migration, invasion, and apoptosis[26-31]. In recent years, a growing body of evidence has associated dysregulated miRNAs with PD, specifically miR-133b [32, 33], miR7 34, 35], miR-7116-5p [36], miR-124 [37, 38], miR-126 [39], and miR-155 [40], to name a few. Although there have been many reports about the role of miRNAs in PD, few have investigated whether miRNAs regulate GLT-1 in PD. Our previous work indicated that miR-543-3p can regulate GLT-1 mRNA (SIc1a2 gene) directly, and that suppressing miR-543-3p can upregulate the expression and function of the GLT-1 protein, which together suggest that miR-543-3p could serve as a potential therapeutic target for PD treatment [41].

Additionally, our high-throughput screening assay detected another promising candidate, miR-30a-5p, as upregulated in MPTP-treated mice, and bioinformatics analysis identified Slc1a2 as a potential target gene for miR-30a-5p [42]. MiR-30a is a member of the miR-30 family, which consists of six distinct mature miRNA sequences: miR-30a, miR-30b, miR-30c-1, miR-30c-2, miR-30d, and miR-30e [43]. To date, there are many reports showing that the dysfunction of miR-30a is correlated with several diseases including chronic myeloid leukemia [44], colorectal cancer [45], and non-small cell lung cancer [46]. However, the mechanism of miR-30a in the progression of PD remains poorly understood.

In this study, we hypothesized that miR-30a-5p contributes to PD pathology by decreasing the expression and function of GLT-1 via the ubiquitin-proteasome degradation pathway. Accordingly, we predicted that miR-30a-5p knockdown would improve the motor deficits and pathological changes in MPTP-treated mice. In testing our hypothesized mechanism of miR-30a-5p in PD, we predicted that miR-30a-5p knockdown would decrease the ubiquitination and degradation of GLT-1, which in turn would upregulate the expression and function of GLT-1. In addition, we also tested whether miR-30a-5p triggered GLT-1 degradation by direct binding or regulated it indirectly via other signaling molecules. Our findings provide strong evidence for miR-30a-5p as a potential therapeutic target for PD.

\section{Materials And Methods}

\section{Animals and MPTP administration}

Ten-week-old, male, C57BL/6 mice were obtained from the Southern Medical University Laboratory Animal Center (Guangzhou, China). The mice were housed under a 12-h/12-h light/dark cycle, with free access to food and water. Mice were randomly divided into four groups: saline+scrambled shRNA, MPTP+scrambled shRNA, saline+miR-30a-5p shRNA, and MPTP+miR-30a-5p shRNA. Depending on their grouping, mice were first intracranially injected with

Page 2/18 
miR-30a-5p or scrambled shRNA (injection details below) and then treated with MPTP or saline. MPTP (Sigma-Aldrich, St. Louis, MO, USA) was administered intraperitoneally (i.p.) for five consecutive days at a dose of $30 \mathrm{mg} / \mathrm{kg}$ free base (MPTP-HCl) in saline, as published in previous studies [14, 15].

\section{Construction and stereotaxic injection of shRNA}

The miR-30a-5p shRNA (miR-30a-5p sponge sequence: ACACGGATCCCTTCCAGTCGAGGATGTTTACATATACCTTCCAGTCGAGGATGTTTACAACATCCTTCCAGTCGAGGATGTTTACATCTTCACTTCCAGTCGAGGATGTT1 was ligated into a pHBLV-U6-ZsGreen-Puro vector (Promega, Madison, USA). The lentivirus vector (LV) was constructed and the virus was packaged by HanBio (Shanghai, China). Before administering MPTP, these shRNA-containing, anti-miR30a-5p LV vectors or scrambled shRNA were stereotaxically injected into the SNpc of the right hemisphere (Target coordinates from Bregma: AP, $-3.0 \mathrm{~mm} ; \mathrm{ML},+1.3 \mathrm{~mm} ; \mathrm{DV},-4.7 \mathrm{~mm}$ ). Three days after the final MPTP injection, behavioral experiments were performed and the animals were euthanized for tissue collection. All animal protocols in this study were approved by the Institutional Animal Care and Use Committee of the Southern Medical University.

\section{Behavioral experiments}

Pole-climbing test. The pole-climbing test was performed as reported previously[47]. Briefly, mice were placed on the peak of a foam ball (diameter: $2.0 \mathrm{~cm}$ ) fixed on a pole (diameter: $1.0 \mathrm{~cm}$; length: $50 \mathrm{~cm}$ ). The time taken to climb from the peak to the bottom of the pole was measured. Each mouse was assessed three times and its mean time was calculated.

Hanging test. Limb movement coordination was assessed using the hanging test, as described previously [48]. Each mouse was suspended three times by its forelimbs hanging on a metal rod (diameter: $1.5 \mathrm{~mm}$ ) and positioned $\sim 30 \mathrm{~cm}$ above a box. The time spent hanging was recorded.

\section{Tissue preparation}

After the behavioral tests, the mice in each group were euthanized to obtain brain sections. Specifically, the mice were anesthetized using an i.p. injection of $4 \%$ chloral hydrate. They then received a thoracotomy and were perfused transcardially with $50 \mathrm{~mL} 0.9 \%$ saline followed by $50 \mathrm{~mL} 4 \%$ paraformaldehyde. The brains were then immediately removed and placed in cold $4 \%$ paraformaldehyde at $4{ }^{\circ} \mathrm{C}$ for $12 \mathrm{~h}$. Next, they were sequentially dehydrated in $20 \%$ and $30 \%$ sucrose. Finally, the brains were embedded in optimum cutting temperature compound (Sakura Finetek, Torrance, CA, USA) and cut into 10- $\mu \mathrm{m}$ sections with a freezing microtome (Leica, Germany). The sections were placed in a $65^{\circ} \mathrm{C}$ incubator for $3.5 \mathrm{~h}$ and then stored at $-80^{\circ} \mathrm{C}$ for immunohistochemistry and immunofluorescent staining.

For other experiments, mice were euthanized three days after their last MPTP injection. Specifically, the mice were anesthetized with an i.p. injection of $4 \%$ chloral hydrate. and then perfused transcardially with $50 \mathrm{~mL}$ of $0.9 \%$ saline to remove traces of blood. The midbrain, striatum, cerebral cortex, and hippocampus were removed and stored at $-80^{\circ} \mathrm{C}$ until use.

\section{Cell culture and miRNA inhibitor/mimic transfection}

Primary cortical astrocytes were obtained from newborn C57BL/6 mice as previously described [16]. In brief, primary astrocytes were cultured in Dulbecco's modified Eagle medium (DMEM/F12; Gibco, NY, USA) supplemented with $10 \%$ fetal calf serum (Excell Bio, Shanghai, China) in $5 \% \mathrm{CO}_{2}$ at $37^{\circ} \mathrm{C}$. An miR-30a-5p inhibitor or mimic and their negative-controls (scrambled miRNA) were designed and synthesized by RiboBio (Guangzhou, China: (miR-30a-5p inhibitor sequence: ACAUUUGUAGGAGCUGACCUUC; miR-30a-5p mimic sequence区 forward UGUAAACAUCCUCGACUGGAAG and reverse: ACAUUUGUAGGAGCUGACCUUC). Astrocytes treated with or without MPP+ (Sigma-Aldrich, St. Louis, MO, USA) were transfected with miR-30a-5p inhibitor/mimic/negative controls according to the manufacturer's instructions provided by RiboBio. Astrocytes were randomly divided into eight groups: (1) Control - incubation in normal culture medium for $48 \mathrm{~h}$. (2) $\mathrm{MPP}^{+}$- incubation in normal culture medium for $24 \mathrm{~h}$ followed by MPP for $24 \mathrm{~h}$. (3) MPP+ + miR30a-5p inhibitor - pretreatment with the miR-30a-5p inhibitor for $24 \mathrm{~h}$ followed by MPP ${ }^{+}$for $24 \mathrm{~h}$. (4) MPP + miR-30a-5p inhibitor control - pretreatment with the miR-30a-5p inhibitor control for $24 \mathrm{~h}$ and then incubation with $\mathrm{MPP}^{+}$for $24 \mathrm{~h}$. (5) MPP + miR-30a-5p mimic - pretreatment with the miR-30a-5p mimic for $24 \mathrm{~h}$ followed by MPP for $24 \mathrm{~h}$. (6) MPP + miR-30a-5p mimic control - pretreatment with the miR-30a-5p mimic control for $24 \mathrm{~h}$ followed by MPP for $24 \mathrm{~h}$. (7) miR-30a-5p inhibitor only - treatment with miRNA inhibitors for $24 \mathrm{~h}$. (8) miR-30a-5p mimic only - treatment with miR-30a-5p mimics for $24 \mathrm{~h}$.

\section{Antagonist or agonist treatment}

To determine whether ubiquitination-induced reduction of GLT-1 expression and function can be reversed by manipulating the expression of different signaling molecules, we treated cultured astrocytes with the following antagonists and agonists purchased from Selleck (Houston, TX, USA): LY294002 (phosphoinositide 3-kinase (PI3Ks) antagonist), staurosporine (protein kinase C (PKC) antagonist), SH-4-54 (signal transducer and activator of transcription 3 (STAT3) antagonist), and MHY1485 (mammalian target of rapamycin (mTOR) agonist). The eight astrocyte groups were incubated either with LY294002 (10 $\mu \mathrm{M}$ for $24 \mathrm{~h}$ ) or staurosporine (1 $\mu \mathrm{M}$ for $10 \mathrm{~min}$ ) or SH-4-54 (300 nM for $24 \mathrm{~h}$ ) or MHY1485 (2 $\mathrm{MM}$ for $24 \mathrm{~h}$ ) or DMSO. Then, glutamate uptake and GLT-1 expression were examined.

\section{L- $\left[{ }^{3} \mathrm{H}\right]-$ Glutamic acid uptake assay}

Astrocytes were seeded in 24-well plates at $\sim 5 \times 105$ cells/cm2. The L-[3H]-Glutamic acid uptake assay was performed as described previously [16]. Briefly, the culture medium was discarded, the astrocytes were washed once with choline solution $(150 \mathrm{mM}$ choline chloride, $5 \mathrm{mM} \mathrm{KPi}, 0.5 \mathrm{mM} \mathrm{MgSO}$, and $0.3 \mathrm{mM}$ $\mathrm{CaCl}_{2}, \mathrm{pH} 7.4$ ), and $0.4 \mu \mathrm{Ci} /$ well L-[$\left[{ }^{3} \mathrm{H}\right]$-Glutamic acid (Perkin Elmer; Boston, MA, USA) was added to each well. The astrocytes were incubated for 10 min at room temperature, and the reaction was stopped by two applications of ice-cold $\mathrm{NaCl}_{\text {solution }(150 \mathrm{mM} \mathrm{NaCl}, 5 \mathrm{mM} \mathrm{KPi}, 0.5 \mathrm{mM} \mathrm{MgSO}}^{4}$, and $0.3 \mathrm{mM} \mathrm{CaCl}$, 
$\mathrm{pH}$ 7.4). A solution of $1 \%$ sodium dodecyl sulfate (SDS) was then added to lyse the cells, and their radioactivity was immediately measured by liquid scintillation counting. These data are from three separate experiments, each performed in triplicate.

\section{Determining the transport activity of synaptosomes}

The midbrain, striatum, cerebral cortex, and hippocampus were individually minced and homogenized with 1:10 (w/v) $0.32 \mathrm{M}$ sucrose solution (0.32 M sucrose, $5 \mathrm{mM} \mathrm{HEPES}, \mathrm{pH} 7.4$ ) and centrifuged at 1,000 $\times \mathrm{g}$ for $15 \mathrm{~min}$. The supernatant was centrifuged further at $15,000 \times g$ for $30 \mathrm{~min}$ at $4{ }^{\circ} \mathrm{C}$, and the resulting precipitate was resuspended in $0.32 \mathrm{M}$ sucrose solution to obtain crude synaptosomes. A bicinchoninic acid (BCA) assay was used to measure the protein concentration of each sample, and then the crude synaptosomes were resuspended to a final concentration of $0.5 \mathrm{mg} / \mathrm{mL}$ in $\mathrm{Kreb}$ 's buffer ( $127 \mathrm{mM}$ $\mathrm{NaCl}, 3.73 \mathrm{mM} \mathrm{KCl}, 1.8 \mathrm{mM} \mathrm{CaCl}_{2}, 1.18 \mathrm{mM} \mathrm{KH}_{2} \mathrm{PO}_{4}, 20 \mathrm{mM} \mathrm{NaHCO}_{3}, 2 \mathrm{mM} \mathrm{ATP}, 2 \mathrm{~g} / \mathrm{L} \mathrm{D}$-glucose, pH 7.4). For the glutamate uptake assay, the synaptosome preparations were placed in a $25^{\circ} \mathrm{C}$ water-bath and $1 \mu \mathrm{Ci} \mathrm{L-}\left[{ }^{3} \mathrm{H}\right]$-glutamic acid was added for $10 \mathrm{~min}$. The reactions were terminated with $5 \mathrm{~mL}$ ice-cold $\mathrm{Kreb}$ 's buffer. The synaptosomes were washed three times with phosphate-buffered saline (PBS) to remove excess labeled glutamate and then filtered through $0.22-$ $\mu \mathrm{m}$ pore-size filter paper. The filter papers containing the rinsed synaptosomes were then placed in scintillation vials containing $3 \mathrm{~mL}$ scintillation cocktail in the dark overnight. The radioactivity was measured the following day by liquid scintillation counting. The glutamate uptake into the synaptosomes was measured as counts per minute (cpm) per mg protein/min [15]. Data were obtained from three different animals, with three independent cultured synaptosome preparations from each animal, and radioactivity measurements were performed in triplicate.

\section{Reverse transcription real-time quantitative PCR (RT-qPCR)}

Total RNA was extracted from total tissue or cells using a Trizol kit according to the manufacturer's instructions (Life Technologies, Carlsbad, CA, USA). Using the PrimeScript RT reagent kit (TaKaRa, Otsu, Japan), RNA was reverse-transcribed to synthesize first-strand cDNA, which was then quantified using the SYBR Premix Ex Taq kit (TaKaRa, Otsu, Japan). For each transcript, a mixture of the following reaction components was prepared to the indicated end-concentration: forward primer $(10 \mu \mathrm{M})$, reverse primer $(10 \mu \mathrm{M})$, and SYBR Green Premix Ex Taq. Fluorescence was detected on a Corbett Research RG-6000 real-time PCR machine (Corbett Life Science, Sydney, Australia). Oligonucleotide primers for Slc1a2 and $\beta$-actin were designed as follows: Slc1a2 forward 5'CGATGAGCCAAAGCACCGAA-3' and reverse 5'-CTGGAGATGATAAGAGGGAGGATG-3'; and $\beta$-actin forward 5'-GGACTCCTATGTGGGTGACG-3' and reverse 5'GTTGGCCTTAGGGTTCAGGG-3'. S/c1a2 mRNA levels were normalized to $\beta$-actin expression. Data are from three separate experiments, and each was performed in triplicate.

\section{Immunohistochemistry assay}

Immunohistochemistry was performed as described previously [15]. Frozen brain sections were recovered at room temperature and antigen retrieval was performed using $0.01 \mathrm{M}$ citrate buffer for $40 \mathrm{~min}$. The sections were permeabilized with $0.3 \%$ Triton X-100 and blocked with $5 \%$ bovine serum albumin (BSA) for $10 \mathrm{~min}$. Then, the sections were incubated with primary antibodies for $15-18 \mathrm{~h}$ at $4^{\circ} \mathrm{C}$. After washing with PBS three times for 5 min, the sections were incubated with secondary antibodies for $2 \mathrm{~h}$ at $37^{\circ} \mathrm{C}$. Antibody-peroxidase complexes were revealed by incubating the sections with 3, 3-diaminobenzidine peroxidase substrate (Maixin, Fujian, China). Finally, the sections were mounted with resin and images were acquired using an Olympus $1 \times 81 \mathrm{FV} 1000$ Laser Scanning Confocal Microscope (Shinjuku, Tokyo, Japan). Image analysis was performed using Image-Pro Plus, version 6.0 (IPP 6.0, Media Cybernetics, Bethesda, MD, USA).

\section{Immunofluorescent double-staining}

Frozen brain sections were recovered at room temperature, fixed in $4 \%$ paraformaldehyde, and then rinsed with PBS three times for 5 min. Next, the sections were permeabilized with $0.3 \%$ Triton X-100 and blocked with $5 \%$ BSA for 10 min. For the colocalization experiments, the brain slices were incubated with primary antibodies (anti-GLT-1 and anti-ubiquitin or anti-EEA1) for 15-18 h at $4^{\circ} \mathrm{C}$, rinsed with PBS three times, and incubated with FITC-conjugated goat antimouse IgG (to bind anti-GLT-1) and TRITC-conjugated goat anti-rabbit IgG (to bind anti-ubiquitin) or Cy3-conjugated donkey anti-goat IgG (to bind anti-EEA1) for $2 \mathrm{~h}$ at $37^{\circ} \mathrm{C}$. DAPI was used to stain cell nuclei. Images were acquired using a laser scanning confocal microscope (Zeiss, Germany) and analyzed using Image-Pro Plus, version 6.0 (IPP 6.0, Media Cybernetics, Bethesda, MD, USA). To investigate the different degradation pathways of GLT-1, only GLT-1 fluorescence that colocalized with ubiquitin (for the ubiquitin-proteasome pathway) or that colocalized with EEA-1 (for the endocytosis-mediated pathway) were measured under each condition.

\section{Isolation of membrane-bound proteins by cell-surface biotinylation}

Cell-surface expression of glutamate transporters was examined using the membrane-impermeable biotinylation reagent EZ-LinkTM Sulfo-NHS-SS-Biotin (Thermo Scientific, Waltham, MA, USA) as described previously [49]. Astrocyte or brain-tissue samples were washed twice with ice-cold PBS (pH 8.0) and incubated with $2.5 \mathrm{~mL}$ EZ-Link Sulfo-NHS-SS-Biotin $(0.5 \mathrm{mg} / \mathrm{mL}$ in PBS) in two successive 20-min incubations on ice with gentle shaking. Then, the samples were washed twice with $100 \mathrm{mM}$ glycine to remove non-reacted biotinylation reagent and lysed on ice for 20 min in $750 \mu \mathrm{L}$ cell-lysis buffer containing a protease inhibitor mixture. After centrifugation at 12,000 rpm for $20 \mathrm{~min}$, debris was removed. Supernatants were transferred to new tubes, and $200 \mu \mathrm{L}$ streptavidin-agarose beads was added to bind the biotin-labeled cell membrane proteins. The samples were then centrifuged at $3,000 \mathrm{rpm}$ for $1 \mathrm{~min}$ at $4^{\circ} \mathrm{C}$, and the supernatant was discarded. This supernatant was washed three times with ice-cold lysis buffer, then washed once with ice-cold PBS and centrifuged for $1 \mathrm{~min}$ at $4^{\circ} \mathrm{C}$. The precipitate from this centrifugation contains membrane-bound proteins, which was diluted with protein-loading buffer and heated at $55^{\circ} \mathrm{C}$ for $30 \mathrm{~min}$ prior to electrophoresis and western blotting.

\section{Western blotting}


First, cells or brain tissues were lysed with radio-immunoprecipitation assay (RIPA) buffer (Beyotime, Shanghai, China) containing 1 mM phenylmethylsulfonyl fluoride (PMSF) (Beyotime, Shanghai, China) for $30 \mathrm{~min}$. Then, the homogenates were centrifuged at $14,000 \times g$ for 15 min and the supernatant was subjected to a BCA assay to determine the protein concentration. Samples of equal protein content were diluted with loading buffer and denatured at $100^{\circ} \mathrm{C}$ for $10 \mathrm{~min}$. Then, the protein samples underwent SDS-polyacrylamide gel electrophoresis (SDS-PAGE) on a $12 \%$ acrylamide gel and were transferred to polyvinylidene difluoride (PVDF) membranes. To block non-specific protein binding, the membranes were incubated in $5 \%$ BSA for $1.5 \mathrm{~h}$ at room temperature with gentle shaking. Then, the membranes were incubated with primary antibodies at $4^{\circ} \mathrm{C}$ for $15-18 \mathrm{~h}$, washed with TBST (Tris-buffered saline containing $0.1 \%$ Tween-20) three times, and incubated with HRP-conjugated secondary antibodies for $1 \mathrm{~h}$ at room temperature. Finally, the membranes were washed again with TBST and enhanced chemiluminescence (Millipore, MA, USA) was used to visualize the protein bands on a Tanon imager system (Shanghai, China). The bands were quantified using ImageJ software (NIH Image, Bethesda, MD). Actin, GAPDH, or integrin- $\beta 1$ immunoreactivity was used as the loading control for each protein. The detail information of antibodies were in table 1.

\section{Dual-luciferase reporter gene experiments}

To verify the regulation of S/c1a2 by miR-30a-5p binding, dual-luciferase reporter vectors were generated by cloning the entire wild-type 3'-untranslated region (3'-UTR) or a mutant 3'-UTR of SIc1a2 into the psiCHECKTM-2 vector (Promega, WI, USA) at the cleavage sites with Notl and Xhol. Then the luciferase reporter constructs containing the $3^{\prime}-$ UTR of mouse S/c1a2 or its seed-sequence mutants were co-introduced with the miR-30a-5p mimic (100 nM) into 293 T cells using Lipofectamine 2000 (Invitrogen). Using this setup, Renilla luciferase fluorescence (Rlu) would decrease if the S/c1a2 3'UTR was bound by the miR-30a-5p mimic. Fluorescence from the Firefly luciferase gene (Flu), also present on the vector, would remain the same in all conditions and is used to normalize fluorescence intensity. After $48 \mathrm{~h}$, all target validation assays were performed with the dual-luciferase reporter system (Vigorous Biotechnology, Beijing, China) according to the manufacturer's instructions. Luciferase activity was determined by the Dual-Luciferase ${ }^{\circledR}$ Reporter Assay System (Promega) and presented as the relative intensity of Rlu/Flu.

\section{Fluorescent in situ hybridization (FISH)}

MiR-30a-5p FISH probes were obtained from FOCOFISH (Guangzhou, China). The sequence of the miR-30a-5p antisense probe was 5'DIGCTTCCAGTCGAGGATGTTTACA-3'DIG. Briefly, the astrocyte cultures or $10 \mu \mathrm{m}$-thick brain sections were incubated at $37^{\circ} \mathrm{C}$ with solution A for 20 min, solution B for $20 \mathrm{~min}$, and $4 \%$ paraformaldehyde for $15 \mathrm{~min}$. Then, the cells or sections were incubated with $200 \mu \mathrm{L}$ hybridization buffer in a $55^{\circ} \mathrm{C}$ water bath for $2 \mathrm{~h}$. In the meantime, the probes were diluted 50 times, denatured at $85^{\circ} \mathrm{C}$ for $3 \mathrm{~min}$, balanced at $37^{\circ} \mathrm{C}$ for 2 min, and then added to each slide or coverslip. Hybridization was carried out in a pre-warmed, humidified box kept in a $42^{\circ} \mathrm{C}$ incubator for $15-18 \mathrm{~h}$. Finally, DAPI was used to stain cell nuclei and the sections or cells were examined using a laser scanning confocal microscope (Zeiss, Germany).

\section{Statistical analysis}

All data are expressed as mean \pm standard error of the mean (SEM). Statistical analysis of the data was performed with the Student's $t$-test to compare two groups or the one-way analysis of variance (ANOVA) with post-hoc multiple comparison and Dunnet testing with SPSS 20.0 software (SPSS Inc., Chicago, IL, USA). Results were considered statistically significant at ${ }^{*} p<0.05$ (and ${ }^{* \star} p<0.01$ ).

\section{Results}

\section{MiR-30a-5p was specifically upregulated in MPP+-treated astrocytes and in the SNpc of MPTP-treated mice.}

Our previously conducted high-throughput sequencing revealed that miR-30a-5p was upregulated significantly in the midbrain of MPTP-treated mice. Bioinformatics analysis with TargetScan, miRanda, and miTarget identified S/c1a2 (the gene of GLT-1) as a potential target gene of miR-30a-5p. Therefore, we chose miR-30a-5p for further study. We verified by RT-qPCR that miR-30a-5p was increased in MPP ${ }^{+}$-treated astrocytes and in the SNpc of MPTP-treated mice We also used a FISH assay to determine miR-30a-5p levels; the results showed that miR-30a-5p was elevated significantly in MPP ${ }^{+}$-treated astrocytes (Fig $1 \mathrm{~b}$, c, $p<0.01$ ) and in the SNpc of MPTP-treated mice (Fig 1d, e, $p<0.01$ ). Taken together, the above results led us to hypothesize that miR-30a-5p might contribute to PD symptoms by regulating the expression and function of GLT-1.

\section{MiR-30a-5p regulated the expression and function of GLT-1 in vitro}

In order to test whether miR-30a-5p affects the expression and function of GLT-1 in vitro, we detected the expression of GLT-1 in both total and membranebound protein fractions of MPP ${ }^{+}$-treated astrocytes. Our data showed that MPP ${ }^{+}$can decrease the expression of total GLT- 1 and membrane-bound GLT- 1 in astrocytes. Nevertheless, when MPP+-exposed astrocytes were treated with an miR-30a-5p inhibitor, the expression of GLT-1 was significantly increased compared with those exposed to the scramble control miRNA $(p<0.05)$. Similarly, treatment with an miR-30a-5p mimic exacerbated the reduction of GLT-1 caused by MPP ${ }^{+}$exposure in both the total and membrane-bound protein fractions $(p<0.05)$ (Fig. 2a-d). We further explored whether miR-30a-5p affected the function of GLT-1 in MPP ${ }^{+}$-treated astrocytes by measuring glutamate uptake under the different treatment conditions. We found that the miR-30a-5p inhibitor improved the ability of glutamate uptake by $\mathrm{MPP}^{+}(p<0.05)$, and the miR-30a-5p mimic aggravated the abnormal function of GLT-1 caused by MPP $(p<0.05, p<0.01)$ (Fig. 2e). Finally, we tested if the above effects were also present at the mRNA level. Similar to our results with the GLT-1 protein, MPP ${ }^{+}$ decreased SIc1a2 mRNA levels but the miR-30a-5p inhibitor was able to reverse this change $(p<0.05)$ (Fig. 2f). Thus, our findings indicated that miR-30a-5p can regulate the expression and function of GLT-1 at both the mRNA and protein levels.

MiR-30a-5p regulated the expression and function of GLT-1 in vivo 
In order to determine whether GLT-1 can be affected by miR-30a-5p in vivo, we used viral-mediated knockdown of miR-30a-5p in MPTP-treated mice. First, we constructed the lentiviral vector (LV) containing miR-30a-5p shRNA and used a FISH assay to test its effect in mice. Our results showed that this LV suppressed the expression of miR-30a-5p by $50 \%(p<0.01)$ (Fig. S1a,b). After lentiviral injection into the SNpc and MPTP administration, we isolated tissue from the midbrain, striatum, cerebral cortex, and hippocampus and retrieved a total protein fraction, membrane protein fraction, complete synaptosome fraction, and total RNA. These different samples were used to detect the GLT-1 protein $(p<0.05, p<0.01)$ (Fig. 3a-d, Fig. S2a,b), glutamate uptake ( $p<0.01)$ (Fig. 3e, Fig. S3a-c), and mRNA expression levels $(p<0.05)$ (Fig. 3f). We found that the expression of total and membrane GLT-1, S/c1a2 mRNA levels, and the glutamate-uptake function of GLT-1 were increased significantly in MPTP-treated mice with shRNA/LV-mediated blockade of miR-30a-5p compared with those MPTP-treated mice injected with the scramble shRNA-containing LV $(p<0.05, p<0.01)$. Taken together, these results confirmed our predictions that the miR30a-5p could regulate GLT-1 in MPTP-treated mice in vivo, and that the expression and function of GLT-1 could be enhanced by knockdown of miR-30a-5p in MPTP-treated mice.

\section{MiR-30a-5p does not bind the 3'-UTR of S/c1a2 mRNA}

Our finding that miR-30a-5p can regulate the expression and function of GLT-1 in vitro and in vivo led to the prediction that S/c1a2 may be a target gene of miR-30a-5p (Fig. 4a). In addition, our preliminary bioinformatics analyses had suggested the same idea. We tested this using dual-luciferase reporter gene experiments, where a decrease in the ratio of Rlu/Flu fluorescence intensity would imply that miR-30a-5p binding caused Slc1a2 mRNA to be degraded rather than translated. However, there was no difference in relative fluorescence between any of the groups, which indicated that there was no direct binding site between miR-30a-5p and S/c1a2 ( $p>0.05$ ) (Fig. 4b). This unexpected finding suggested that the regulation of GLT-1 by miR-30a-5p in MPTP-treated mice occurs indirectly via one of the cell's other signaling pathways.

\section{MiR-30a-5p regulated GLT-1 through the PKCa pathway in the SNpc of MPTP-treated mice}

Since we found that GLT-1 expression and function was indeed regulated by miR-30a-5p but that Slc1a2 was not a target gene of miR-30a-5p, we hypothesized that miR-30a-5p regulates GLT-1 via an undetermined pathway. As potential intermediaries between miR-30a-5p and GLT-1, we chose several signaling molecules that have been associated with PD, namely PI3K, PKCa, STAT3, and mTOR[50-54]. As expected from their known roles in PD, western blots of the active, phosphorylated (p-) form of these proteins showed that PI3K ( $p<0.01)$ (Fig. 4c, d), PKCa $(p<0.01)$ (Fig. 4c, e), and STAT3 ( $p<0.05, p<0.01$ ) (Fig. 4c, f) were activated while mTOR $(p<0.01$ ) (Fig. 4c, g) was suppressed in the midbrain of MPTP-treated mice. When MPTP-treated mice were injected with miR-30a-5p shRNA, p-PI3K, p-PKCa, p-STAT3, and p-mTOR expression were restored to control levels.

To specifically study the effect of these signaling molecules on GLT-1 function in astrocytes, we conducted glutamate-uptake assays in cultured astrocytes exposed to a PI3K antagonist (LY294002), PKCa antagonist (staurosporine), STAT3 antagonist (SH-4-54), or mTOR agonist (MHY1485). We found that neither the PI3K antagonist (LY294002) $(p<0.01)$ (Fig. 4h) nor the STAT3 antagonist (SH-4-54) $(p<0.01)$ (Fig. 4i) changed the abnormal function of GLT-1 caused by $\mathrm{MPP}^{+}$treatment of astrocyte cultures. In contrast, the PKCa antagonist (staurosporine) $(p<0.01)$ (Fig. 4j) and the mTOR agonist (MHY1485) ( $\left.p<0.01\right)($ Fig. $4 \mathrm{k}$ ) did improve the abnormal function of GLT-1 in MPP+-treated astrocytes Therefore, our data supported that miR-30a-5p indirectly regulated the function of GLT-1 through the PKCa and mTOR pathways.

Next, we tested whether miR-30a-5p used these same two pathways to regulate the expression of GLT-1. Western blots for GLT-1 in total and membrane fractions showed that the PKCa antagonist (staurosporine) reversed the decrease in membrane-bound GLT-1 caused by MPP ${ }^{+}$, but did not affect total levels of GLT-1 $(p<0.01)$ (Fig. 5a-d). In contrast, the mTOR agonist (MHY1485) was unable to restore any of the GLT-1 expression deficits in MPP ${ }^{+}$-treated astrocytes; both total GLT-1 $(p<0.01)$ (Fig. 5e, g) and membrane-bound GLT-1 $(p<0.01)$ (Fig. $5 f, h)$ levels were still decreased. Taken together, these results suggest that miR-30a-5p can regulate both the function and expression of GLT-1 through the PKCa pathway.

\section{Ubiquitin-mediated degradation of GLT-1 was hindered by miR-30a-5p knockdown or PKCa antagonist (staurosporine)}

Since we established that miR-30a-5p can regulate the expression of GLT-1 in vitro and in vivo, we wanted to test if this regulation was carried out by hindering the degradation pathways of GLT-1. To this end, we used immunofluorescent double-staining in MPP ${ }^{+}$-treated astrocytes and of the SNpc of MPTPtreated mice to detect ubiquitin and early endosome antigen (EEA-1). Ubiquitin and EEA-1 would serve as markers for the ubiquitin-proteasome degradation pathway and the endocytosis degradation pathway, respectively. We found that both degradation pathways of GLT-1 were upregulated in MPP ${ }^{+}$-treated astrocytes $(p<0.01)$ (Fig. S4a-d) and in MPTP-treated mice $(p<0.01)$ (Fig. 6a-d). However, shRNA-mediated knockdown of miR-30a-5p reversed the upregulated ubiquitination but not the increased EEA-1 expression $(p<0.01)$ (Fig. 6a-d). Thus, our data confirmed that miR-30a-5p can regulate the expression of GLT-1 by preventing its degradation by the ubiquitin-proteasome pathway.

Next, we wanted to test whether miR-30a-5p regulated GLT-1 ubiquitination through PKCa or mTOR. We once again used immunofluorescent double-staining to determine the effect of the PKCa antagonist (staurosporine) or mTOR agonist (MHY1485) on the ubiquitin-mediated degradation pathway. The results showed that staurosporine reversed the increase in ubiquitination caused by $\mathrm{MPP}^{+}(p<0.01)$ (Fig. 6e, f), but MHY1485 did not ( $\left.p<0.01\right)$ (Fig. $6 \mathrm{~g}$, h). Taken together, our data indicated that miR-30a-5p can regulate the ubiquitin-mediated degradation of membrane-bound GLT-1 through the PKCa pathway.

\section{MiR-30a-5p shRNA improved the motor deficits and pathological changes in MPTP-treated mice.}

In order to assess the functional outcome of miR-30-5p knockdown in MPTP-treated mice, behavioral tests were performed to determine motor capacity. ShRNA-mediated miR-30a-5p knockdown in MPTP-treated mice shortened their pole-climbing time and prolonged their holding time in the hanging test $(p<$ 0.01) (Fig. 7a, b). These results clearly showed that miR-30a-5p knockdown can alleviate motor deficits in MPTP-treated mice. 
Next, we used immunohistochemistry to test whether miR-30a-5p knockdown could also ameliorate the pathological changes observed in MPTP-treated mice. In line with our predictions, the expression of a-Syn was reduced significantly in the SNpc of MPTP-treated mice injected with miR-30a-5p shRNA compared with MPTP and scramble RNA-treated mice $(p<0.01)$ (Fig. 7c). Furthermore, miR-30a-5p knockdown reversed the MPTP-induced reduction in the number of TH-positive neurons in the SNpc and TH-positive neuron density in the striatum $(p<0.01)$ (Fig. 7d, e). These results indicated that miR-30a-5p knockdown had a neuroprotective effect in MPTP-treated mice.

Since astrocytic activation and microgliosis are some of the hallmark characteristics of PD $[14,15,55,56]$, we tested the effect of miR-30a-5p knockdown on these phenotypes in the SNpc. We found that the MPTP-induced increases in GFAP expression (a marker of activated astrocytes) and Iba-1 (microglial marker) were ameliorated by miR-30a-5p shRNA $(p<0.01)$ (Fig. 7f, g). So, we can conclude that miR-30a-5p knockdown attenuated astrogliosis and reactive microgliosis. Subsequently, improved the expression and function of GLT-1 in an MPTP model of PD in vivo were increased.

\section{Discussion}

Glutamate transporters can remove extracellular glutamate from the synaptic cleft to prevent glutamate excitotoxicity [57]. Glutamate excitotoxicity mediated by dysfunctional glutamate transporters is a crucial part of the pathogenesis of PD; many studies have shown that increasing glutamate-transporter expression and function can improve the progress of neurodegenerative diseases, including PD [14-16, 58, 59]. In our previous studies, we reported that ceftriaxone improved MPP+-induced dysfunction of GLT-1 in astrocytes by promoting the membrane expression of GLT-1 and attenuated the apoptosis of astrocytes by suppression of the NF-KB/JNK/c-Jun signaling pathway [16]. We also found that rapamycin can preserve the astrocytic expression of glutamate transporters and glutamate reuptake, which is protective against MPTP [ $\left.{ }^{14}\right]$. Evidence from our group and others confirm that glutamate transporters play an important role in the development of PD, but its mechanism of regulation had not been well elucidated thus far.

It has been reported that the expression of protein is regulated by microRNAs, and several studies have investigated miRNAs in PD. He Q et al. found that MPP+ is taken up by microglia through organic cation transporter 3 (ОСТ3) and downregulates miR-7116-5p, which is a miRNA target of tumor necrosis factor alpha (TNF-a) [36]. They reported that this MPP+-induced downregulation of miR-7116-5p elicited the production of TNF-a in microglia [36]. Furthermore, they found an improvement in miR-7116-5p expression in the microglia of MPTP-treated mice where the production of TNF-a and activation of glia was inhibited, which prevented the loss of DA neurons [36]. Kim J et al. found that microRNAs miR-27a and miR-27b can regulate PINK1 expression at the translational level and autophagic clearance of damaged mitochondria [60]. Their data further supported a novel negative regulatory mechanism of PINK1-mediated mitophagy by miR-27a and miR-27b [60].

Other studies have investigated miRNAs in the context of glutamate excitotoxicity. Aw et al. found that miR-263a limited glutamate-receptor levels in a subset of glia by targeting Grik, Nmdar1, and Nmdar2 in drosophila, protecting the cells from excitotoxicity [61]. They also found that loss of miR-263a led to the death of a specific population of ensheathing glia, which was correlated with severe climbing defects in C57BL/6 mice [61]. A different study by Harraz et al. showed that neuronal miR-223 regulated glutamate receptors; specifically, miR-223 can control neuronal excitability in response to glutamate by targeting the AMPA receptor subunit GluR2 and the NMDA receptor subunit NR2B, both of which are glutamate receptors [62]. The presynaptic activity of miR-1000 has also been shown to modulate synaptic plasticity via regulation of vesicular glutamate transporter expression [63].

Despite the number of reports about the role of microRNAs in glutamate excitotoxicity, not many detail the regulatory mechanisms of miRNAs on glutamate transporters. Morel et al. found that exosomes isolated from neuron-conditioned medium contained miR-124a and are directly internalized into astrocytes to increase astrocytic GLT1 levels[64]. Moreover, miR-124a is decreased in the spinal-cord tissue of SOD1G93A (mouse model of amyotrophic lateral sclerosis [ALS]), and exogenous delivery of miR-124a in vivo prevented further pathological loss of GLT-164. Yang Z et al. found that GLT-1 gene is a target of miR-107, and that miR-107-induced suppression of GLT-1 caused the accumulation of glutamate after ischemic stroke [65]. A recent study from our group provided evidence that miR-543-3p regulated the glutamate transporter GLT-1 in PD [41]. Furthermore, our data showed that inhibiting miR-543-3p in vivo and in vitro improved the expression and function of GLT-1 and improved the motor defects and pathological changes in MPTP-treated mice [41]. Until our current study on miR-30a-5p, miR-543-3p was likely the first and only identified miRNA that targeted GLT-1 in PD.

Our current study investigated the potential role of miR-30a-5p in the progression of PD. We found that miR-30a-5p regulated the expression and function of GLT-1, and miR-30a-5p knockdown improved the abnormal expression and function of GLT-1 in vitro and in vivo in a PD mouse model. Contrary to our prediction, a dual-luciferase reporter assay showed that S/c1a2 was not a target gene of miR-30a-5p. This led us to the discovery that miR-30a-5p indirectly regulated GLT-1 by the PD-related signaling molecule PKCa. Activation of PKCa appears to be a crucial step for mediating the biological effects of miR-30a-5p, at least partly. PKCa does not contain a binding site for miR-30a-5p, therefore, how exactly it is regulated by miR-30a-5p requires further research. Others have reported that PKC promoted the degradation pathway of GLT-1 [15, 66-68]. Specifically, PKC activation induced the ubiquitination of GLT-1 [69], which mediated its interaction with the endocytic machinery for degradation [68]. Our group also used co-immunoprecipitation assays to show that PKC activation can regulate the ubiquitination of GLT-1 [15].

In this study, we used immunofluorescent double-staining to detect the ubiquitin-mediated degradation pathway and the endocytosis degradation pathway in MPP ${ }^{+}$-treated astrocytes and in the SNpc of MPTP-treated mice. We found both degradation pathways of GLT-1 upregulated in MPTP-treated mice, and miR30a-5p shRNA reversed this upregulated degradation only by the ubiquitin pathway, not the endocytosis pathway (Fig. 6a-d). Dysfunction of the ubiquitinproteasome degradation pathway is important in the pathogenesis of PD; an increasing number of reports are implicating ubiquitin in PD. a-Syn inclusions in Lewy bodies can also be ubiquitinated in PD [70]. Parkin (PARK2), another gene mutated in familial PD, is an E3-ubiquitin ligase that plays an important role in selecting proteins for ubiquitination [71, 72]. Our group previously found that Nedd4-2-mediated ubiquitination hindered glutamate-transporter trafficking between the membrane and cytoplasm, consequently decreasing the expression and function of glutamate transporters in the membrane [15]. Accordingly, 
Nedd4-2 knockdown promoted glutamate function and glutamate-transporter expression in vitro and in vivo, while also improving behavioral and pathological changes in MPTP-treated mice [15] These parallel lines of evidence from the literature strongly suggest that ubiquitination of GLT-1 is important in PD.

In this study, we showed that miR-30a-5p knockdown ameliorated the movement defects in MPTP-treated mice, did not increased the number of TH-positive neurons in the SNpc, and augmented the TH cell density in the striatum, but prevented the dopaminergic neuronal loss. MiR-30a-5p knockdown also decreased the a-Syn density in the SNpc of MPTP-treated mice. These results suggest that miR-30a-5p knockdown protected the animal from the effects of MPTP toxicity and we conclude that this protection is mediated by miR-30a-5p's regulation of GLT-1.

\section{Conclusion}

We demonstrated that miR-30a-5p can regulate the expression and function of GLT-1 by ubiquitination of these glutamate transporters through the PKCa pathway in vitro and in vivo (Fig 8). We also showed that miR-30a-5p knockdown ameliorated movement deficits and attenuated pathological change in MPTP-treated mice via increasing glutamate transporters. We conclude that miR-30a-5p should be considered a promising therapeutic target for the treatment of PD.

\section{Abbreviations}

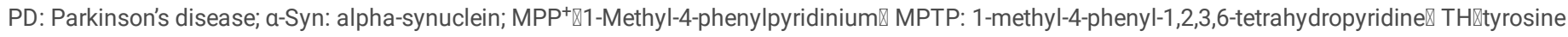
hydroxylase $\mathbb{D}$ A: dopamine GLT囚glutamate transporter》 PKCa: Protein Kinase C a; miRNAs: microRNAs;EAAT: excitatory-amino-acid transporters; STAT: signal transducer and activator of transcription; mTOR: mammalian target of rapamycin; BCA : bicinchoninic acid; PMSF: phenylmethylsulfonyl fluoride; SDS: sodium dodecyl sulfate.

\section{Declarations}

\section{Acknowledgments}

Not applicable

\section{Author's contributions}

S.Q. designed the research. X.M., X.Z., X.W., and C.Z. performed the experiments. S.Q., J.Z., and KKL.Y. analyzed the data. S.Q., and X.M. wrote the manuscript.

\section{Funding}

This work was funded by grants from the National Natural Science Foundation of China (81870991, U1603281, and 31570716), the Program for Changjiang Scholars and Innovative Research Team in University (IRT_16R37), the Clinical Research startup program of Southern Medical University by High-level University Construction Funding of Guangdong Provincial Department of Education (LC2016PY055), and the key innovational technology project of Guangzhou (2018-1202-SF-0019).

\section{Availability of data and materials}

All data supporting the conclusions of this study are included in the article.

\section{Ethics approval and consent to participate}

The animals used in this study were treated in accordance with protocols approved by the Institutional Animal Care and Use Committee of Southern Medical University, China.

\section{Competing interests}

The authors declare that they have no conflict of interests.

\section{References}

1. Olanow CW, Tatton WG. Etiology and pathogenesis of Parkinson's disease. Annu Rev Neurosci 1999;22:123-144.

2. Miklya I, Goltl P, Hafenscher F, Pencz N. [The role of parkin in Parkinson's disease]. Neuropsychopharmacol Hung 2014;16:67-76.

3. Sanders LH, McCoy J, Hu X, Mastroberardino PG, Dickinson BC, Chang CJ, et al. Mitochondrial DNA damage: molecular marker of vulnerable nigral neurons in Parkinson's disease. Neurobiol Dis 2014;70:214-223.

4. Koros C, Simitsi A, Stefanis L. Genetics of Parkinson's Disease: Genotype-Phenotype Correlations. Int Rev Neurobiol 2017;132:197-231.

5. Kim CY, Alcalay RN. Genetic Forms of Parkinson's Disease. Semin Neurol 2017;37:135-146. 
6. Aguirre-Gamboa R, Joosten I, Urbano PCM, van der Molen RG, van Rijssen E, van Cranenbroek B, et al. Differential Effects of Environmental and Genetic Factors on T and B Cell Immune Traits. Cell Rep 2016;17:2474-2487.

7. Ter Horst R, Jaeger M, Smeekens SP, Oosting M, Swertz MA, Li Y, et al. Host and Environmental Factors Influencing Individual Human Cytokine Responses. Cell 2016;167:1111-1124 e1113.

8. Hirsch EC, Hunot S. Neuroinflammation in Parkinson's disease: a target for neuroprotection? Lancet Neurol 2009;8:382-397.

9. Chao Y, Wong SC, Tan EK. Evidence of inflammatory system involvement in Parkinson's disease. Biomed Res Int 2014;2014:308654.

10. Macchi B, Di Paola R, Marino-Merlo F, Felice MR, Cuzzocrea S, Mastino A. Inflammatory and cell death pathways in brain and peripheral blood in Parkinson's disease. CNS Neurol Disord Drug Targets 2015;14:313-324.

11. Ambrosi G, Cerri S, Blandini F. A further update on the role of excitotoxicity in the pathogenesis of Parkinson's disease. J Neural Transm (Vienna) 2014;121:849-859.

12. Gardoni F, Di Luca M. Targeting glutamatergic synapses in Parkinson's disease. Curr Opin Pharmacol 2015;20:24-28.

13. Blandini F. An update on the potential role of excitotoxicity in the pathogenesis of Parkinson's disease. Funct Neurol 2010;25:65-71.

14. Zhang Y, He X, Wu X, et al. Rapamycin upregulates glutamate transporter and IL-6 expression in astrocytes in a mouse model of Parkinson's disease. Cell Death Dis 2017;8:e2611.

15. Zhang Y, He X, Meng X, Lei M, Wei Z, Zhang X, et al. Regulation of glutamate transporter trafficking by Nedd4-2 in a Parkinson's disease model. Cell Death Dis 2017;8:e2574.

16. Zhang Y, Zhang X, Qu S. Ceftriaxone Protects Astrocytes from MPP(+) via Suppression of NF-kappaB/JNK/c-Jun Signaling. Mol Neurobiol 2015;52:78-92.

17. Arriza JL, Eliasof S, Kavanaugh MP, Amara SG. Excitatory amino acid transporter 5, a retinal glutamate transporter coupled to a chloride conductance. Proc Natl Acad Sci U S A 1997;94:4155-4160.

18. Arriza JL, Fairman WA, Wadiche JI, Murdoch GH, Kavanaugh MP, Amara SG. Functional comparisons of three glutamate transporter subtypes cloned from human motor cortex. J Neurosci 1994;14:5559-5569.

19. Fairman WA, Vandenberg RJ, Arriza JL, Kavanaugh MP, Amara SG. An excitatory amino-acid transporter with properties of a ligand-gated chloride channel. Nature 1995;375:599-603.

20. Kanai Y, Hediger MA. Primary structure and functional characterization of a high-affinity glutamate transporter. Nature 1992;360:467-471.

21. Pines G, Danbolt NC, Bjoras M, Zhang Y, Bendahan A, Eide L, et al. Cloning and expression of a rat brain L-glutamate transporter. Nature 1992;360:464467.

22. Storck T, Schulte S, Hofmann K, Stoffel W. Structure, expression, and functional analysis of a $\mathrm{Na}(+)$-dependent glutamate/aspartate transporter from rat brain. Proc Natl Acad Sci U S A 1992;89:10955-10959.

23. Eliasof S, Arriza JL, Leighton BH, Kavanaugh MP, Amara SG. Excitatory amino acid transporters of the salamander retina: identification, localization, and function. J Neurosci 1998;18:698-712.

24. Anderson CM, Swanson RA. Astrocyte glutamate transport: review of properties, regulation, and physiological functions. Glia 2000;32:1-14.

25. Bartel DP. MicroRNAs: genomics, biogenesis, mechanism, and function. Cell 2004;116:281-297.

26. Alvarez-Garcia I, Miska EA. MicroRNA functions in animal development and human disease. Development 2005;132:4653-4662.

27. Wei WF, Han LF, Liu D, Wu LF, Chen XJ, Yi HY, et al. Orthotopic Xenograft Mouse Model of Cervical Cancer for Studying the Role of MicroRNA-21 in Promoting Lymph Node Metastasis. Int J Gynecol Cancer 2017;27:1587-1595.

28. Bai X, Geng J, Zhou Z, Tian J, Li X. MicroRNA-130b improves renal tubulointerstitial fibrosis via repression of Snail-induced epithelial-mesenchymal transition in diabetic nephropathy. Sci Rep 2016;6:20475.

29. Li J, Yang S, Yan W, Yang J, Qin YJ, Lin XL, et al. MicroRNA-19 triggers epithelial-mesenchymal transition of lung cancer cells accompanied by growth inhibition. Lab Invest 2015;95:1056-1070.

30. Shen G, Rong X, Zhao J, Yang X, Li H, Jiang H,et al. MicroRNA-105 suppresses cell proliferation and inhibits PI3K/AKT signaling in human hepatocellular carcinoma. Carcinogenesis 2014;35:2748-2755.

31. Wang H, An H, Wang B, Liao Q, Li W, Jin X,et al. miR-133a represses tumour growth and metastasis in colorectal cancer by targeting LIM and SH3 protein 1 and inhibiting the MAPK pathway. Eur J Cancer 2013;49:3924-3935.

32. Kim J, Inoue K, Ishii J, Vanti WB, Voronov SV, Murchison E,et al. A MicroRNA feedback circuit in midbrain dopamine neurons. Science 2007;317:12201224.

33. Hebert SS, De Strooper B. Molecular biology. miRNAs in neurodegeneration. Science 2007;317:1179-1180.

34. Junn E, Lee KW, Jeong BS, Chan TW, Im JY, Mouradian MM. Repression of alpha-synuclein expression and toxicity by microRNA-7. Proc Natl Acad Sci U S A 2009;106:13052-13057.

35. Choi DC, Chae YJ, Kabaria S, Chaudhuri AD, Jain MR, Li H, et al. MicroRNA-7 protects against 1-methyl-4-phenylpyridinium-induced cell death by targeting RelA. J Neurosci 2014;34:12725-12737.

36. He Q, Wang Q, Yuan C, Wang Y. Downregulation of miR-7116-5p in microglia by MPP(+) sensitizes TNF-alpha production to induce dopaminergic neuron damage. Glia 2017;65:1251-1263.

37. Saraiva C, Paiva J, Santos T, Ferreira L, Bernardino L. MicroRNA-124 loaded nanoparticles enhance brain repair in Parkinson's disease. J Control Release 2016;235:291-305. 
38. Wang H, Ye Y, Zhu Z, Mo L, Lin C, Wang Q, et al. MiR-124 Regulates Apoptosis and Autophagy Process in MPTP Model of Parkinson's Disease by Targeting to Bim. Brain Pathol 2016;26:167-176.

39. Kim W, Lee Y, McKenna ND, Yi M, Simunovic F, Wang Y, et al. miR-126 contributes to Parkinson's disease by dysregulating the insulin-like growth factor/phosphoinositide 3-kinase signaling. Neurobiol Aging 2014;35:1712-1721.

40. Thome AD, Harms AS, Volpicelli-Daley LA, Standaert DG. microRNA-155 Regulates Alpha-Synuclein-Induced Inflammatory Responses in Models of Parkinson Disease. J Neurosci 2016;36:2383-2390.

41. Wu X, Meng X, Tan F, Jiao Z, Zhang X, Tong H, et al. Regulatory Mechanism of miR-543-3p on GLT-1 in a Mouse Model of Parkinson's Disease. ACS Chem Neurosci 2019;10:1791-1800.

42. Wu X, Meng X, Tan F, Jiao Z, Zhang X, Tong H, et al. Regulatory Mechanism of miR-543-3p on GLT-1 in a Mouse Model of Parkinson's Disease. ACS Chem Neurosci 2019.

43. Chang TC, Yu D, Lee YS, Wentzel EA, Arking DE, West KM, et al. Widespread microRNA repression by Myc contributes to tumorigenesis. Nat Genet 2008;40:43-50.

44. Liu Y, Song Y, Ma W, Zheng W, Yin H. Decreased microRNA-30a levels are associated with enhanced ABL1 and BCR-ABL1 expression in chronic myeloid leukemia. Leuk Res 2013;37:349-356.

45. Baraniskin A, Birkenkamp-Demtroder K, Maghnouj A, Zollner H, Munding J, Klein-Scory S, Reinacher-Schick A, et al. MiR-30a-5p suppresses tumor growth in colon carcinoma by targeting DTL. Carcinogenesis 2012;33:732-739.

46. Kumarswamy R, Mudduluru G, Ceppi P, Muppala S, Kozlowski M, Niklinski J, et al. MicroRNA-30a inhibits epithelial-to-mesenchymal transition by targeting Snai1 and is downregulated in non-small cell lung cancer. Int J Cancer 2012;130:2044-2053.

47. Ju MS, Kim HG, Choi JG, Ryu JH, Hur J, Kim YJ, et al. Cassiae semen, a seed of Cassia obtusifolia, has neuroprotective effects in Parkinson's disease models. Food Chem Toxicol 2010;48:2037-2044.

48. Arai N, Misugi K, Goshima Y, Misu Y. Evaluation of a 1-methyl-4-phenyl-1,2,3,6-tetrahydropyridine (MPTP)-treated C57 black mouse model for parkinsonism. Brain Res 1990;515:57-63.

49. Rong X, Tan F, Wu X, Zhang X, Lu L, Zou X, et al. TM4 of the glutamate transporter GLT-1 experiences substrate-induced motion during the transport cycle. Sci Rep 2016;6:34522.

50. Zhu Z, Wang YW, Ge DH, Lu M, Liu W, Xiong J, et al. Downregulation of DEC1 contributes to the neurotoxicity induced by MPP(+) by suppressing PI3K/Akt/GSK3beta pathway. CNS Neurosci Ther 2017;23:736-747.

51. Qin H, Buckley JA, Li X, Liu Y, Fox TH, 3rd, Meares GP,et al. Inhibition of the JAK/STAT Pathway Protects Against alpha-Synuclein-Induced Neuroinflammation and Dopaminergic Neurodegeneration. J Neurosci 2016;36:5144-5159.

52. Fragkouli A, Doxakis E. miR-7 and miR-153 protect neurons against MPP(+)-induced cell death via upregulation of mTOR pathway. Front Cell Neurosci 2014;8:182.

53. Maiese K. Targeting molecules to medicine with mTOR, autophagy and neurodegenerative disorders. Br J Clin Pharmacol 2016;82:1245-1266.

54. Do Van B, Gouel F, Jonneaux A, Timmerman K, Gele P, Petrault M,et al. Ferroptosis, a newly characterized form of cell death in Parkinson's disease that is regulated by PKC. Neurobiol Dis 2016;94:169-178.

55. Sun H, Liang R, Yang B, Zhou Y, Liu M, Fang F, et al. Aquaporin-4 mediates communication between astrocyte and microglia: Implications of neuroinflammation in experimental Parkinson's disease. Neuroscience 2016;317:65-75.

56. Ho SC, Hsu CC, Pawlak CR, Tikhonova MA, Lai TJ, Amstislavskaya TG,et al. Effects of ceftriaxone on the behavioral and neuronal changes in an MPTPinduced Parkinson's disease rat model. Behav Brain Res 2014;268:177-184.

57. Mehta A, Prabhakar M, Kumar P, Deshmukh R, Sharma PL. Excitotoxicity: bridge to various triggers in neurodegenerative disorders. Eur J Pharmacol 2013;698:6-18.

58. Lin CL, Kong Q, Cuny GD, Glicksman MA. Glutamate transporter EAAT2: a new target for the treatment of neurodegenerative diseases. Future Med Chem 2012;4:1689-1700.

59. Kong Q, Chang LC, Takahashi K, Liu Q, Schulte DA, Lai L,et al. Small-molecule activator of glutamate transporter EAAT2 translation provides neuroprotection. J Clin Invest 2014;124:1255-1267.

60. Kim J, Fiesel FC, Belmonte KC, Hudec R, Wang WX, Kim C, et al. miR-27a and miR-27b regulate autophagic clearance of damaged mitochondria by targeting PTEN-induced putative kinase 1 (PINK1). Mol Neurodegener 2016;11:55.

61. Aw SS, Lim IKH, Tang MXM, Cohen SM. A Glio-Protective Role of mir-263a by Tuning Sensitivity to Glutamate. Cell Rep 2017;19:1783-1793.

62. Harraz MM, Eacker SM, Wang X, Dawson TM, Dawson VL. MicroRNA-223 is neuroprotective by targeting glutamate receptors. Proc Natl Acad Sci U S A 2012;109:18962-18967.

63. Verma P, Augustine GJ, Ammar MR, Tashiro A, Cohen SM. A neuroprotective role for microRNA miR-1000 mediated by limiting glutamate excitotoxicity. Nat Neurosci 2015;18:379-385.

64. Morel L, Regan M, Higashimori H, Ng SK, Esau C, Vidensky S, et al. Neuronal exosomal miRNA-dependent translational regulation of astroglial glutamate transporter GLT1. J Biol Chem 2013;288:7105-7116.

65. Yang ZB, Zhang Z, Li TB, Lou Z, Li SY, Yang H, et al. Up-regulation of brain-enriched miR-107 promotes excitatory neurotoxicity through down-regulation of glutamate transporter-1 expression following ischaemic stroke. Clin Sci (Lond) 2014;127:679-689. 
66. Gonzalez-Gonzalez IM, Garcia-Tardon N, Gimenez C, Zafra F. PKC-dependent endocytosis of the GLT1 glutamate transporter depends on ubiquitylation of lysines located in a C-terminal cluster. Glia 2008;56:963-974.

67. Kalandadze A, Wu Y, Robinson MB. Protein kinase C activation decreases cell surface expression of the GLT-1 subtype of glutamate transporter. Requirement of a carboxyl-terminal domain and partial dependence on serine 486. J Biol Chem 2002;277:45741-45750.

68. Gonzalez MI, Robinson MB. Protein kinase C-dependent remodeling of glutamate transporter function. Mol Interv 2004;4:48-58.

69. Garcia-Tardon N, Gonzalez-Gonzalez IM, Martinez-Villarreal J, Fernandez-Sanchez E, Gimenez C, Zafra F. Protein kinase C (PKC)-promoted endocytosis of glutamate transporter GLT-1 requires ubiquitin ligase Nedd4-2-dependent ubiquitination but not phosphorylation. J Biol Chem 2012;287:19177-19187.

70. Liani E, Eyal A, Avraham E, Shemer R, Szargel R, Berg D,et al. Ubiquitylation of synphilin-1 and alpha-synuclein by SIAH and its presence in cellular inclusions and Lewy bodies imply a role in Parkinson's disease. Proc Natl Acad Sci U S A 2004;101:5500-5505.

71. Imai Y, Soda M, Inoue H, Hattori N, Mizuno Y, Takahashi R. An unfolded putative transmembrane polypeptide, which can lead to endoplasmic reticulum stress, is a substrate of Parkin. Cell 2001;105:891-902.

72. Shimura H, Hattori N, Kubo S, Mizuno Y, Asakawa S, Minoshima S, et al. Familial Parkinson disease gene product, parkin, is a ubiquitin-protein ligase. Nat Genet 2000;25:302-305.

\section{Table}

\begin{tabular}{|l|l|l|l|}
\hline Antibodies & Species & Dilution & Manufacturer \\
\hline anti-GFAP & Mouse & $1: 200$ & Cell Signaling Technology \\
\hline anti-Iba-1 & Rabbit & $1: 100$ & Wako (Osaka, Japan) \\
\hline anti-GLT-1 & Rabbit & $1: 1000$ & Millipore (Bedford, MA, USA) \\
\hline anti-TH & Rabbit & $1: 100$ & Millipore (Bedford, MA, USA) \\
\hline anti-ubiquitin & Mouse & $1: 100$ & Santa Cruz Biotechnology (Santa Cruz, CA, USA) \\
\hline anti-integrin $\beta 1$ & Mouse & $1: 1000$ & Santa Cruz Biotechnology (Santa Cruz, CA, USA) \\
\hline anti-EEA1 & Mouse & $1: 100$ & Santa Cruz Biotechnology (Santa Cruz, CA, USA) \\
\hline anti- $\alpha$-synuclein & Mouse & $1: 100$ & Santa Cruz Biotechnology (Santa Cruz, CA, USA) \\
\hline anti-phospho-PKC $\alpha$ (Thr638) & Mouse & $1: 1000$ & EnoGene (Nanjing, China) \\
\hline anti-PKCo & Mouse & $1: 1000$ & EnoGene (Nanjing, China) \\
\hline anti-phospho-STAT3 (Tyr705) & Mouse & $1: 1000$ & EnoGene (Nanjing, China) \\
\hline anti-STAT3 & Mouse & $1: 1000$ & EnoGene (Nanjing, China) \\
\hline anti-phospho-PI3-kinase p85- $\alpha$ (Tyr607) & Mouse & $1: 1000$ & EnoGene (Nanjing, China) \\
\hline anti-PI3-kinase p85- $\alpha$ & Mouse & $1: 1000$ & EnoGene (Nanjing, China) \\
\hline anti-phospho-Akt (Ser473) & Mouse & $1: 1000$ & EnoGene (Nanjing, China) \\
\hline anti-Akt & Mouse & $1: 1000$ & EnoGene (Nanjing, China) \\
\hline anti-phospho-NF-kB p65(Ser276) & Mouse & $1: 1000$ & EnoGene (Nanjing, China) \\
\hline anti-NF-kB p65 & Mouse & $1: 1000$ & EnoGene (Nanjing, China) \\
\hline Anti-phospho-mTOR & Mouse & $1: 1000$ & EnoGene (Nanjing, China) \\
\hline anti-mTOR & Mouse & $1: 1000$ & EnoGene (Nanjing, China) \\
\hline anti-Actin & Mouse & $1: 1000$ & Beyotime (Shanghai, China) \\
\hline anti-GAPDH & Rabbit & $1: 1000$ & Beyotime (Shanghai, China) \\
\hline anti-GAPDH & Mouse & $1: 1000$ & Beyotime (Shanghai, China) \\
\hline HRP-conjugated goat anti-mouse & Goat & $1: 1000$ & Boster (Wuhan, China) \\
\hline HRP-conjugated goat anti- rabbit & Goat & $1: 1000$ & Boster (Wuhan, China) \\
\hline TRITC-conjugated goat anti-rabbit & Goat & $1: 1000$ & Boster (Wuhan, China) \\
\hline FITC-conjugated goat anti-mouse & Goat & $1: 1000$ & Boster (Wuhan, China) \\
\hline
\end{tabular}

Table 1. List of antibodies used in experiment.

\section{Figures}


a

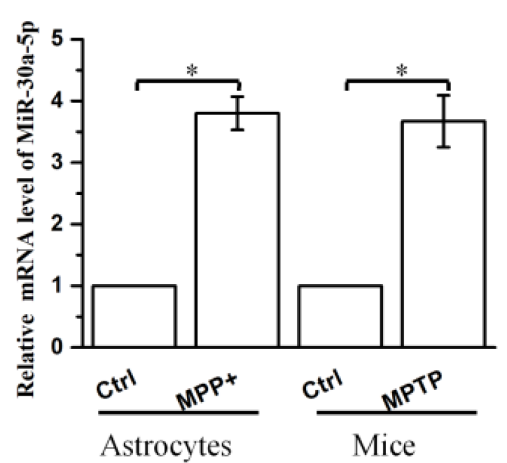

d
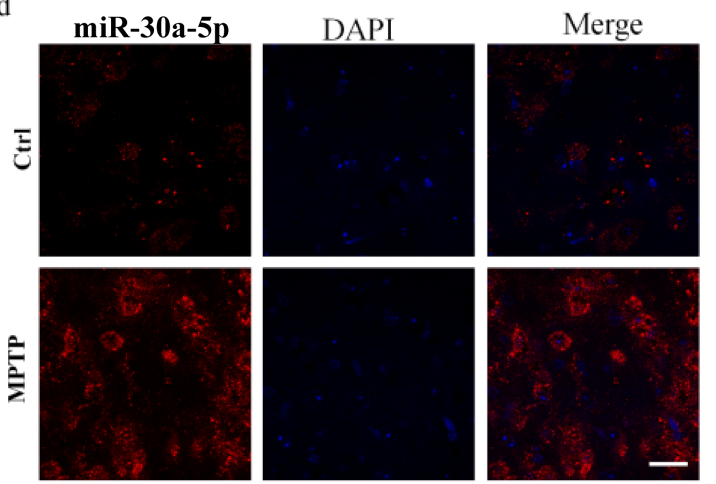

Mice
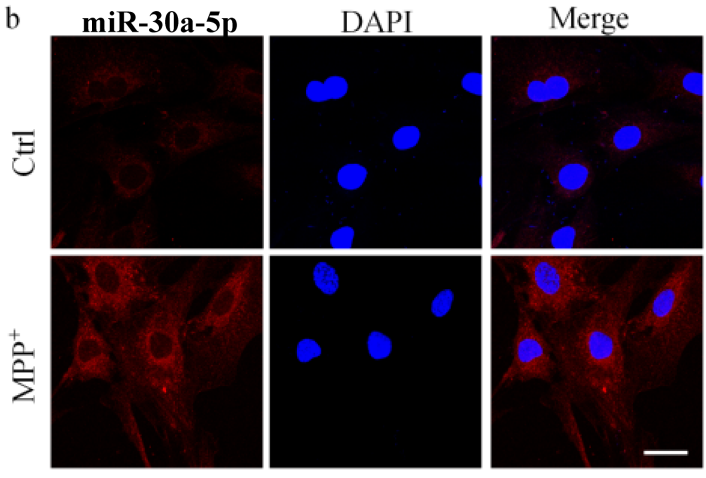

Astrocytes

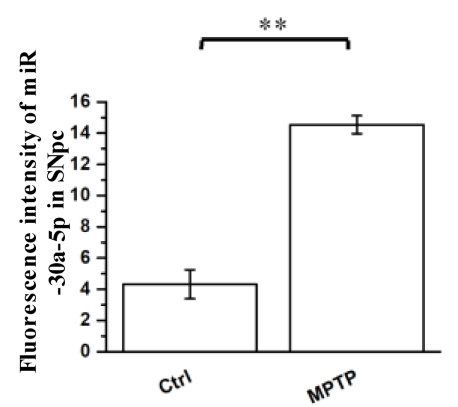

crir

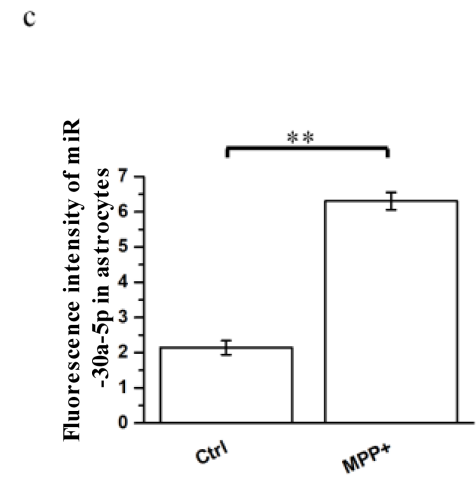

\section{Figure 1}

MiR-30a-5p is specifically upregulated in MPP+-treated astrocytes and in the SN of MPTP-treated mice. (a) MiR-30a-5p is detected in MPP+-treated astrocytes ( $n=3$ per group) and in the substantia nigra pars compacta (SNpc) of MPTP-treated mice ( $n=3$ per group) by RT-qPCR. The control (Ctrl) group in astrocytes and mice were treated with saline. (b) Fluorescence in situ hybridization of miR-30a-5p in astrocytes after a 24-h MPP+ or saline (Ctrl) treatment Confocal images on the left show miR-30a-5p in red and DAPI staining of cell nuclei in blue. Quantification of the fluorescence is shown on the right. $\mathrm{n}=6$ coverslips per group (c) Fluorescence in situ hybridization of miR-30a-5p in the SNpc of MPTP- or saline-treated mice. Confocal images on the left show miR-30a-5p in red and DAPI staining of cell nuclei in blue (d). Quantification of the fluorescence is shown on the right (e). Data are expressed as the mean \pm SEM with the Student's t-test to compare two groups or one-way ANOVA. * $p<0.05$, ** $p<0.01$. Scale bar in (b) and (d): $30 \mu \mathrm{m}$ 


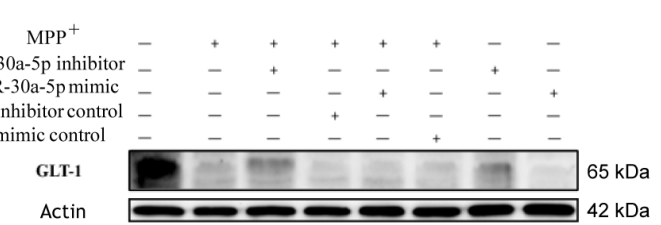

c

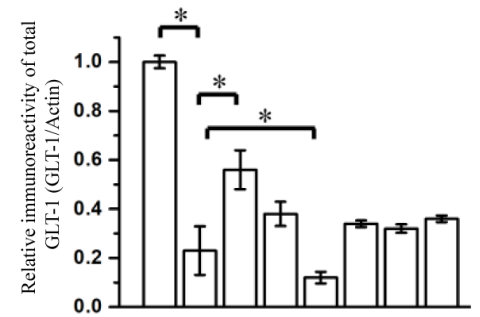

$\mathrm{MPP}^{+}$

miR-30a-5p inhibitor +++++-

miR-30a-5pmimic $--_{-}+-_{-}+$

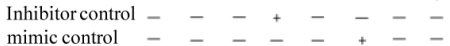

$\mathbf{e}$

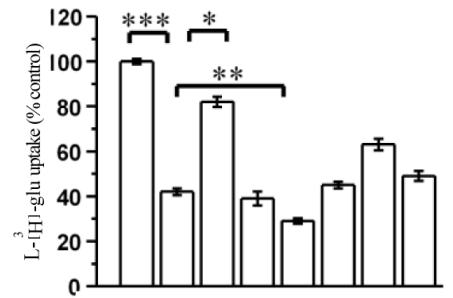

$\mathrm{MPP}^{+}$

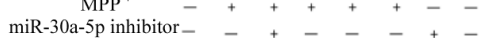

miR-30a-5pmimic ${ }_{-}-_{-}+{ }_{-}-_{-}+$

Inhibitor control

mimic control

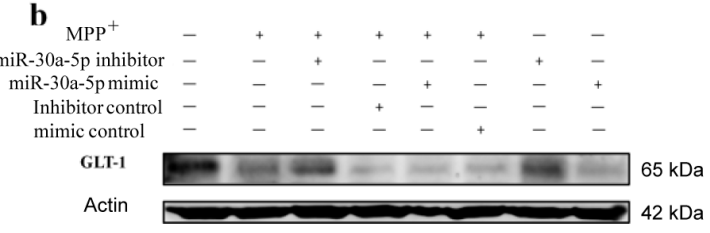

d

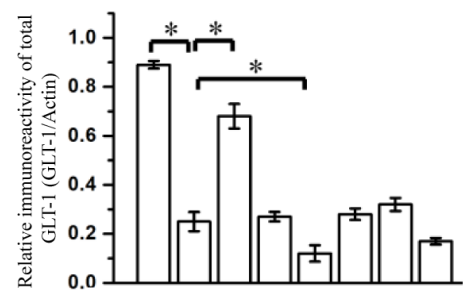

$\mathrm{MPP}^{+}$

miR-30a-5p inhibitor -

miR-30a-5pmimic $-C_{-}+-{ }_{-}+-{ }_{-}$

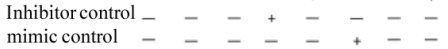

f

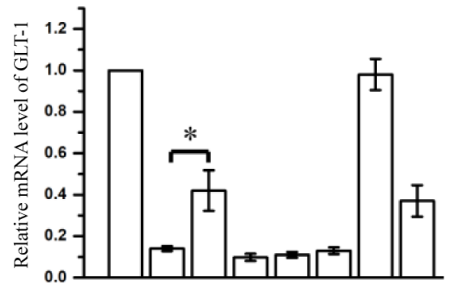

$\mathrm{MPP}^{+}-+++++-$

$\underset{\text { miR-30a-5pmimic }}{\operatorname{miR}-30 a-5 p \text { inhibitor }}++-+-+$

$\begin{array}{cccccccc}\text { Inhibitor control } & - & - & - & + & - & - & +\end{array}$

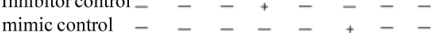

\section{Figure 2}

MiR-30a-5p regulates the expression and function of glutamate transporter GLT-1 in vitro. Primary cortical astrocytes were incubated with miR-30a-5p inhibitor, inhibitor control, miR-30a-5p mimic, or mimic control for $24 \mathrm{~h}$, then incubated with MPP+ for $24 \mathrm{~h}$, after which the following assays were conducted. Western blots of (a) total GLT-1 protein and (b) membrane-bound GLT1. Quantification of the immunoreactivity in (a) and (b) are displayed in (c) for total GLT-1 and (d) for membrane-bound GLT-1 (e) Slc1a2 mRNA expression was detected using RT-qPCR. (f) GLT-1 transporter activity was determined by measuring L-[3H]glutamic acid uptake. Data are expressed as the mean \pm SEM of at least three experiments and analyzed by one-way ANOVA. ${ }^{*} p<0.05, * \star p<0.01, * \star \star p<0.001$ 
a

b

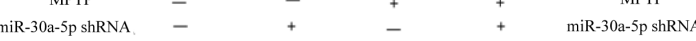

GLT-1

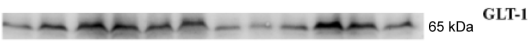

Actin

$42 \mathrm{kDa}$ Actin

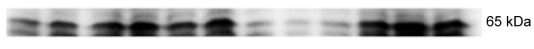

d
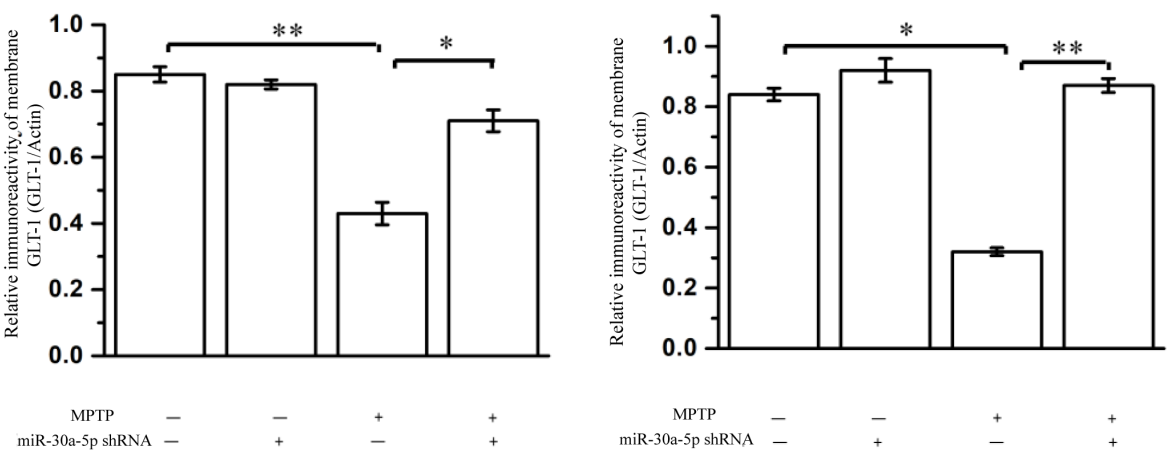

$\mathbf{e}$
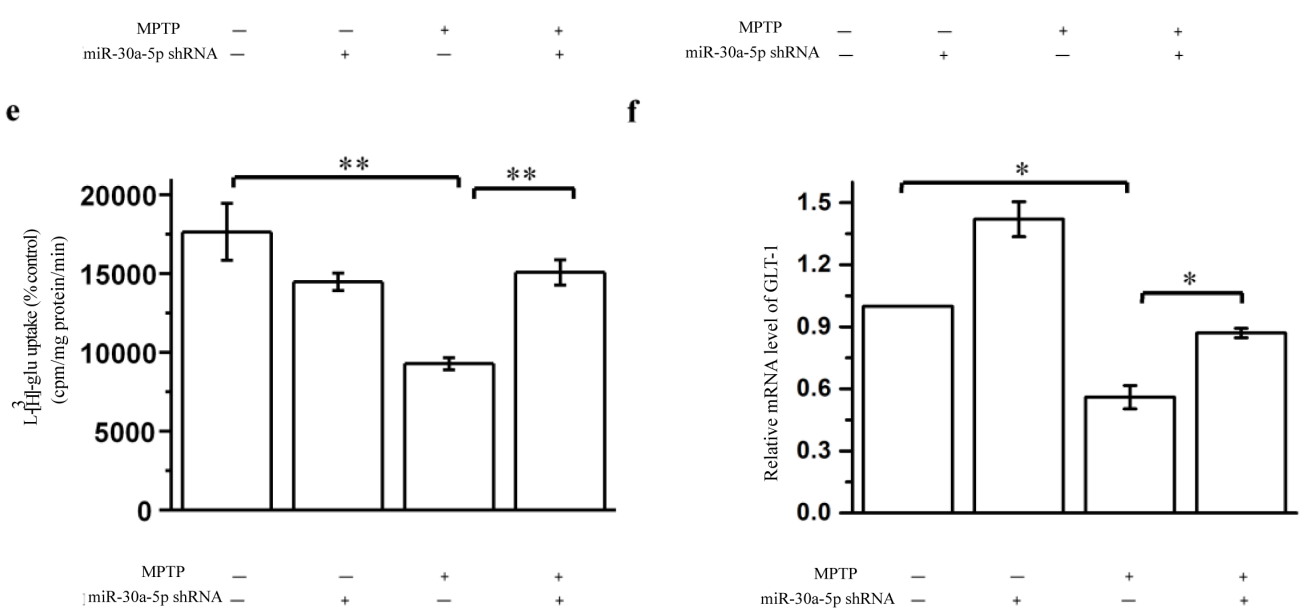

Figure 3

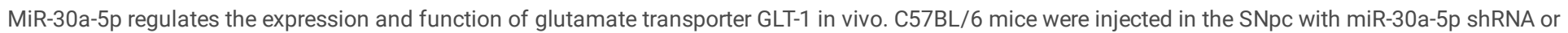

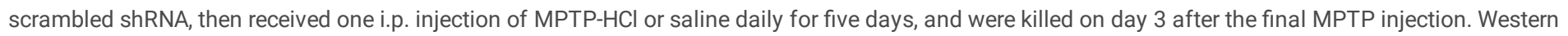

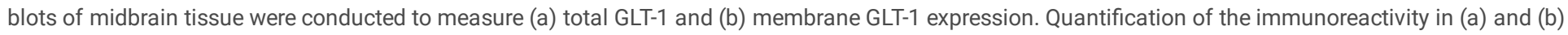

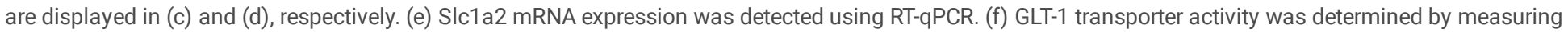

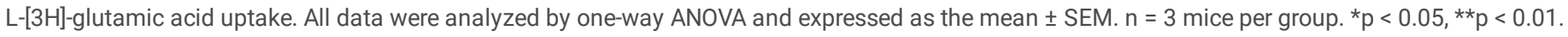


b

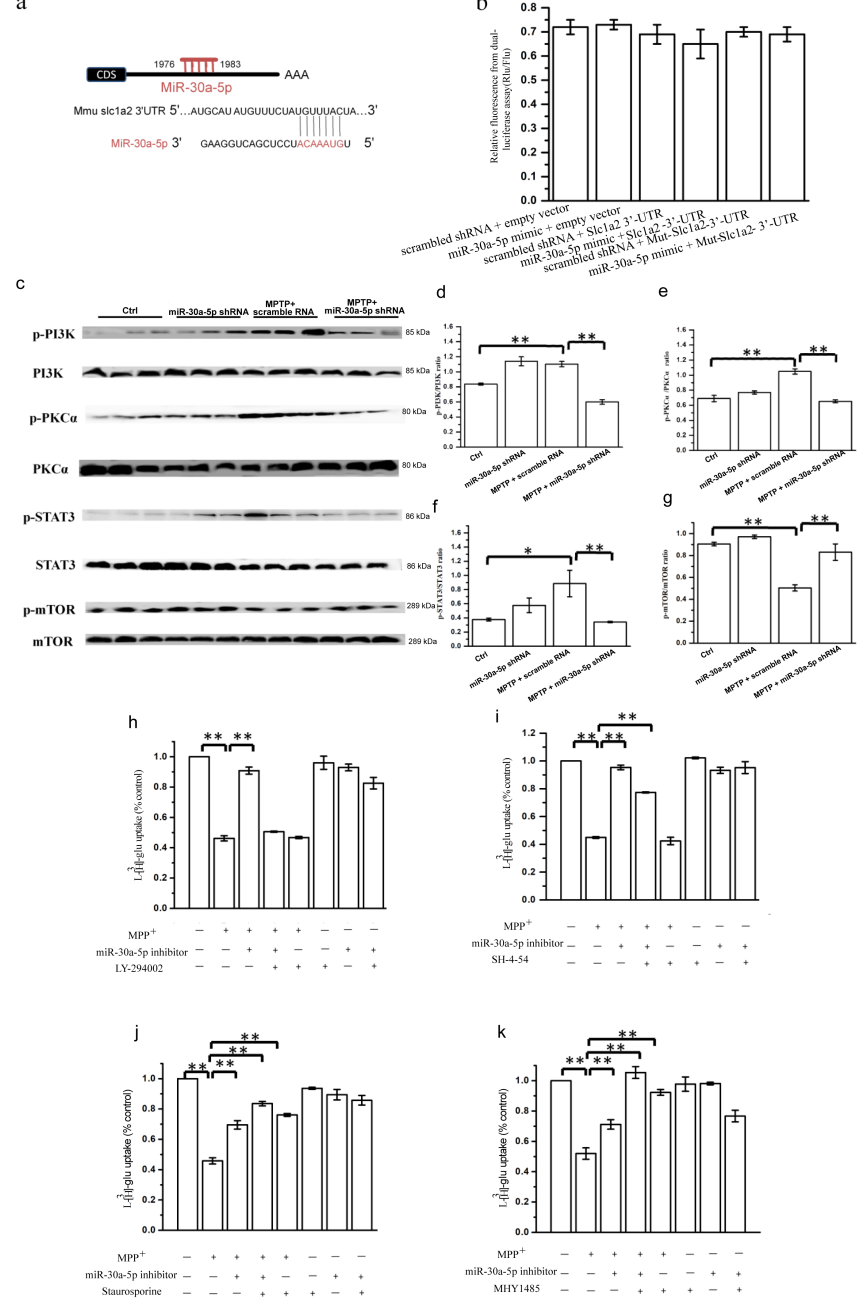

Figure 4

The effect of miR-30a-5p on signaling protein expression and transporter activity of GLT-1. (a) The coding sequence (CDS) of GLT-1 mRNA is followed by its 3'UTR sequence, where the predicted target site of miR-30a-5p lies between amino acid 1976 and 1983. Sequence alignment of the Slc1a2 3'-UTR in mouse (Mus.musculus, Mmu) and miR-30a-5p. (b) Dual-luciferase reporter assay to determine binding of the Slc1a2 3'-UTR by miR-30a-5p.293T cells were cotransfected with reporter vectors containing either a wildtype or mutant 3'-UTR of GLT-1 (Slc1a2-3'-UTR and Mut-SIc1a2-3'-UTR, respectively) and a miR-30a-5p mimic. The cells were harvested $24 \mathrm{~h}$ later and fluorescence was detected. Empty vector (psicheck2) and scrambled shRNA (150608-NC) were used as negative controls for the luciferase reporter vectors and the miR-30a-5p mimic. C57BL/6 mice were injected in the SNpc with miR-30a-5p shRNA or scrambled shRNA, then received one i.p. injection of MPTP-HCl or saline daily for five days, and were euthanized on day 3 after the final MPTP injection. Midbrain tissue was prepared for western blots of total PI3K, PKCa, STAT3, and mTOR protein, as well as their active, phosphorylated (p-) forms. (c) Images of the total and phosphorylated protein bands under the different conditions: "Ctrl” (scrambled shRNA+saline), "miR-30a-5p shRNA" (miR-30a-5p shRNA+saline), "MPTP" (MPTP+scrambled shRNA), and "MPTP+miR-30a-5p shRNA". (d-g) Quantifications of the phosphorylated proteins normalized by the total level of the corresponding protein (p-protein/total protein). GLT-1 transporter activity in primary cortical astrocytes incubated with or without (h) LY294002, a PI3K antagonist, (i) staurosporine, a PKCa antagonist, (j) SH-4-54, a STAT3 antagonist, or (k) MHY1485, an mTOR agonist, for 24 h, then incubated with an miR$30 \mathrm{a}-5 \mathrm{p}$ inhibitor or control inhibitor for $24 \mathrm{~h}$, and finally incubated with MPP+ for $24 \mathrm{~h}$. The data were analyzed by one-way ANOVA and are expressed as the mean \pm SEM. $n=3$ per group. Only relevant differences are indicated in the figure by ${ }^{*} p<0.05,{ }^{*} p<0.01$, ns $=$ not significant. 


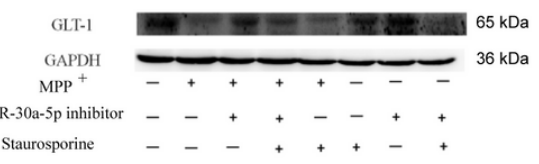

c

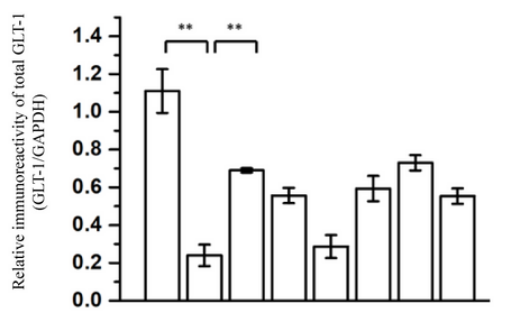

$\mathrm{MPP}^{+}-++++--$

miR-30a-5p inhibitor $-\quad++--++$

Staurosporine $\quad-\quad-+++-+$

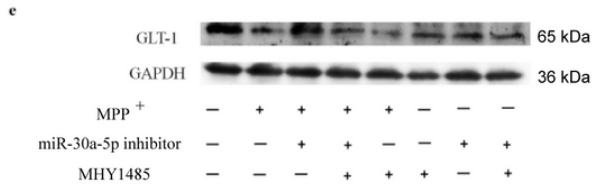

g
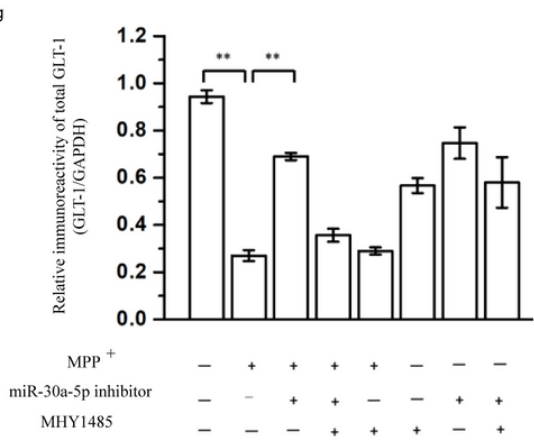

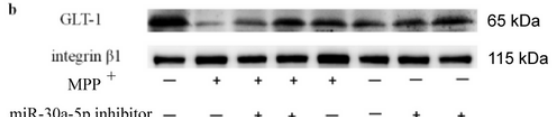

miR-30a-5p inhibitor $-\quad++-\quad++$

Staurosporine $--{ }^{-}++-+$

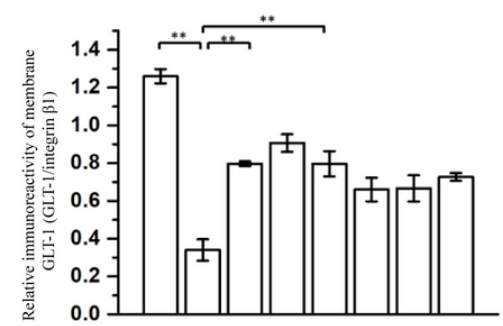

MPP

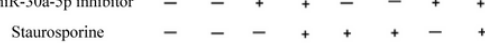

GLT-1 $-2-0=65 \mathrm{kDa}$

${ }_{\text {integrin } \beta 1} \longrightarrow-\longrightarrow-C-115 \mathrm{kDa}$

miR-30a-5p inhibitor $-+_{+}^{+}+-++$

MHY1485 $-\quad-++++-+$

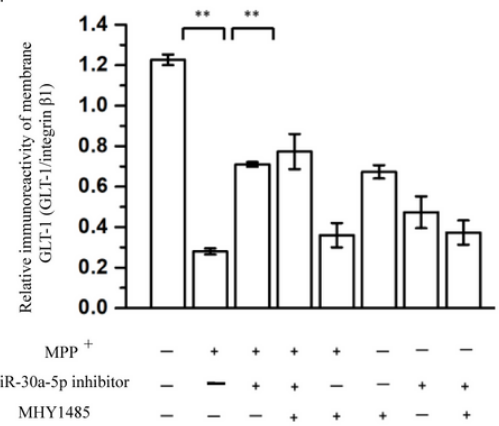

\section{Figure 5}

Staurosporine reverses the decrease in GLT-1 in the membrane of MPP+-treated astrocytes. Primary cortical astrocytes were incubated with or without staurosporine or MHY1485 for $24 \mathrm{~h}$, then incubated with an miR-30a-5p inhibitor or control inhibitor for $24 \mathrm{~h}$, and finally incubated with MPP+ or saline for 24 h. Western blots were conducted to measure the effect of staurosporine on (a) total GLT-1 and (b) membrane GLT-1 expression. Quantification of the immunoreactivity in (a) and (b) are displayed in (c) and (d), respectively. Similarly, western blots were performed to measure the effect of MHY1485 on (e) total GLT-1 and (f) membrane GLT-1 expression. $(g)$ and (h) show the quantifications of the immunoreactivity in (e) and (f), respectively. The data were analyzed by one-way ANOVA and are expressed as the mean \pm SEM of at least three experiments. Only relevant differences are indicated in the figure by * $<$ $0.05,{ }^{* *} \mathrm{p}<0.01,{ }^{* * *} \mathrm{p}<0.001, \mathrm{~ns}=$ not significant 

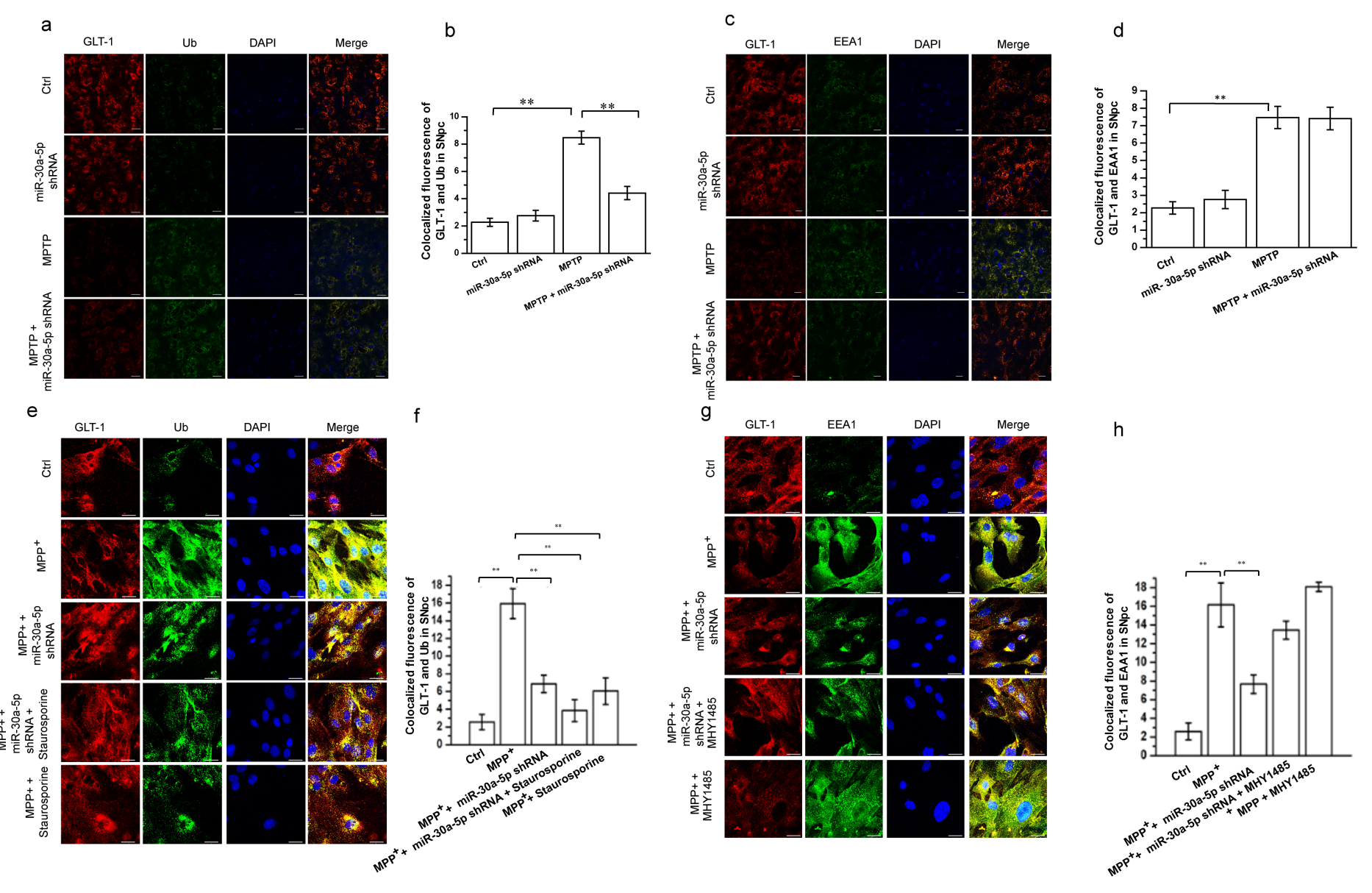

Figure 6

MiR-30a-5p shRNA decreases the ubiquitin-mediated degradation of GLT-1 in the SN of MPTP-treated mice through the PKCa pathway. C57BL/6 mice were injected in the substantia nigra pars compacta (SNpc) with miR-30a-5p shRNA or scrambled shRNA, then received one i.p. injection of MPTP-HCl or saline daily for five days, and were euthanized on day 3 after the final MPTP injection. (a) Immunofluorescent double-staining was performed to determine the effect of miR-30a-5p shRNA on the ubiquitin degradation pathway of GLT-1, with GLT-1 in red, ubiquitin (Ub) in green, and nuclear DAPI staining in blue. (b) Quantification of the co-localized fluorescence (ubiquitinated GLT-1). $n=6$ mice per group. (c) The effect of miR-30a-5p shRNA on the endocytosis degradation pathway of GLT-1 was detected by immunofluorescent double-staining, with GLT-1 in red, EEA1 in green, and nuclear DAPI staining in blue. (d) Quantification of the co-localized fluorescence. $n=6$ mice per group. (e) The effect of staurosporine on the ubiquitin-mediated degradation of GLT-1 was detected by immunofluorescent double-staining of cultured astrocytes, with GLT-1 in red, ubiquitin (Ub) in green, and nuclear DAPI staining in blue. (f) Quantification of the colocalized fluorescence (ubiquitinated GLT-1). $n=6$ independent cultures per group. (g and $h$ ) The same as experiment and quantification as in (e) and ( $f$ ) except that the effect of MHY1485 was tested on the ubiquitin-mediated degradation of GLT-1 in astrocytes. $n=6$ independent cell cultures per group. Data were analyzed by one-way ANOVA and are expressed as the mean $\pm \mathrm{SEM}$. ${ }^{\star} \mathrm{p}<0.05,{ }^{\star \star} \mathrm{p}<0.01$. All scale bars: $30 \mu \mathrm{m}$ 要

Figure 7

MiR-30a-5p shRNA improves the motor deficits and pathological changes in MPTP-treated mice. (a) MiR-30a-5p shRNA decreased the time taken for MPTPtreated mice to climb from the peak to base of the pole in the pole-climbing motor test. (b) In the hanging test of motor ability, miR-30a-5p shRNA prolonged the hanging time of MPTP-treated mice. (c) Immunohistochemistry (IHC) staining (left) and quantification (right) showing a-Syn expression in the SNpc of MPTP-treated mice with and without miR-30a-5p shRNA. Scale bar: $30 \mu \mathrm{m}$. (d and e) IHC staining (left) and quantification (right) showing TH expression in the SNpc (scale bar: $100 \mu \mathrm{m}$ ) and striatum (scale bar: $50 \mu \mathrm{m}$ ) of MPTP-treated mice with and without miR-30a-5p. (f and g) IHC staining (left) and quantification (right) showing astrogliosis (GFAP-positive cells) and reactive microgliosis (Iba-1-positive cells) in the SNpc of MPTP-treated mice with and without miR-30a5p. Scale bar: $30 \mu \mathrm{m}$. Data were analyzed by one-way ANOVA and are expressed as the mean $\pm \mathrm{SEM}$. $\mathrm{n}=10$ mice per group for the behavioral tests in (a) and (b); $\mathrm{n}=6$ mice per group for the IHC in (c-g). ${ }^{\star} \mathrm{p}<0.05,{ }^{*} \mathrm{p}<0.01$

展

Figure 8

The potential mechanism of miR-30a-5p regulates the expression and function of GLT-1.

\section{Supplementary Files}


This is a list of supplementary files associated with this preprint. Click to download.

- SupplementaryFigure1.tif

- SupplementaryFigure3.tif

- SupplementaryFigure2.tif

- SupplementaryFigure4.tif 